\title{
Scanning Microprobe Matrix-Assisted \\ Laser Desorption Ionization (SMALDI) \\ Mass Spectrometry: Instrumentation for \\ Sub-Micrometer Resolved LDI and MALDI \\ Surface Analysis
}

\author{
Bernhard Spengler and Martin Hubert \\ Institute of Inorganic and Analytical Chemistry, Justus-Liebig University Giessen, Giessen, Germany
}

\begin{abstract}
A new instrument and method is described for laterally resolved mass spectrometric surface analysis. Fields of application are in both the life sciences and the material sciences. The instrument provides for imaging of the distribution of selected sample components from natural and artificial surfaces. Samples are either analyzed by laser desorption ionization (LDI) time-of-flight mass spectrometry or, after preparation with a suitable matrix, by matrixassisted laser desorption ionization (MALDI) mass spectrometry. Areas of $100 \times 100 \mu \mathrm{m}$ are scanned with minimal increments of $0.25 \mu \mathrm{m}$, and between 10,000 and 160,000 mass spectra are acquired per image within 3 to $50 \mathrm{~min}$ (scan rate up to 50 pixels per s). The effective lateral resolution is in the range of 0.6 to $1.5 \mu \mathrm{m}$ depending on sample properties, preparation methods and laser wavelength. Optical investigation of the same sample area by UV confocal scanning laser microscopy was found to be very attractive in combination with scanning MALDI mass analysis because pixel-identical images can be created with both techniques providing for a strong increase in analytical information. This article describes the method and instrumentation, including first applicational examples in elemental analysis, imaging of pine tree roots, and investigation of MALDI sample morphology in biomolecular analysis. (J Am Soc Mass Spectrom 2002, 13, 735-748) @ 2002 American Society for Mass Spectrometry
\end{abstract}

$\mathrm{L}$ aser microprobe mass spectrometry was developed more than 25 years ago as a method for localized chemical analysis of biological samples or of, e.g., semiconductor surfaces [1, 2]. Several limitations (especially in sensitivity, mass range, and isotope discrimination) of other microprobing techniques which were well established at that time, such as electron probe $\mathrm{X}$-ray microanalysis, could be overcome using lasers for vaporization and ionization of micrometer areas. Instruments were developed for transmission mode analysis of thin sections and for reflection mode analysis of bulk surfaces. Because of its attractive features, the method found broad application over the years. The various fields of research assisted by laser microprobing have been reviewed in several papers [3-6].

The main drawback of the classical laser microprobe mass analysis (LAMMA) technique is its restriction to elemental analysis. Only few and specialized applications were reported for molecular analysis of biological

Published online April 23, 2002

Address reprint requests to Dr. B. Spengler, Institute of Inorganic and Analytical Chemistry, Justus-Liebig University Giessen, Schubertstr. 60, D-35392 Giessen, Germany. E-mail: bernhard.spengler@anorg.chemie.unigiessen.de samples with this technique [6-9]. The reason for this limitation is the same as for the limited applicability of (non-highly focused) laser desorption ionization (LDI) in general. Before matrix-assisted laser desorption ionization (MALDI) was developed [10], analysis of organic and inorganic material was possible by LDI, but analytical success was strongly dependent on the individual sample parameters, such as spectral absorbance, volatility or ionization potential [11,12]. Addition of a matrix to a sample of interest provided for a rather common behavior of almost any type of sample with respect to ionizability, analytical sensitivity, molecular stability etc. $[13,14]$. MALDI has nowadays become the ionization method of choice for solid-state related bioanalytical mass spectrometry [15] while electrospray ionization (ESI) has reached a comparable level of importance for liquid-phase related mass analysis [16]. The overall interest in MALDI is still growing in all fields where analytical information is coupled to surface immobilization or surface separation techniques, especially when structural information can be acquired from sample surfaces by postsource decay (PSD) analysis [17].

During the recent years, another aspect of analytical information came into focus in MALDI mass spectro- 
metry, which is the lateral or positional information, as is examined with the LAMMA technique for elemental analysis. Highly sensitive investigation of single cells, neurons, or tissue areas is a field of dramatically growing consideration [18-24]. Due to instrumental and methodological limitations, MALDI imaging has so far been limited to a lateral resolution of approximately $30 \mu \mathrm{m}[18,25-30]$, limiting its application to relatively large structures.

Secondary ion mass spectrometry (SIMS) is another analytical technique capable of imaging inorganic or organic matter. Both SIMS and MALDI imaging have been reviewed recently in reference [31]. Among the major differences between these techniques are the accessible mass range and the analytical depth. While SIMS provides analytical information on elements and small organic molecules, MALDI allows identification of large biomolecules such as proteins. In the so-called static SIMS mode [32], analytical information is obtained from the first monolayer only. Static SIMS is therefore known as a real surface analytical technique. MALDI and laser desorption in general, on the other hand, are techniques which extract analytical information from a greater depth with each laser shot. Depending on the focus diameter used, the ablation depth is between nanometers and micrometers [3, 4]. Spatial resolution in static SIMS can be as high as $100 \mathrm{~nm}$ to $1 \mu \mathrm{m}$, but often has to be reduced to values in the range of $10 \mu \mathrm{m}$ in order to increase the number of secondary ions accessible.

Scanning near field optical microscopy (SNOM) is a well-known method to increase lateral resolution above the classical optical limit of diffraction. Optical resolution in the nanometer range is achievable with this method. Efforts to use SNOM for LDI mass spectrometry were reported recently, but without success so far in detecting larger molecular ions [33].

Combining LAMMA and MALDI appears to be an obvious and very promising goal. Its realization, however, is not straightforward. First, the lateral resolution necessary for most biological applications has to be considerably higher than originally achieved with the (reflection mode) LAMMA 1000 instrument (which was in the range of $10 \mu \mathrm{m}$ ). Second, application of the matrix to a sample of interest is not as straightforward as for general MALDI mass analysis. MALDI preparation is known to depend on formation of a homogeneous liquid-phase mixture of matrix and analyte before crystallization. For laterally resolved analysis of biological specimen, on the other hand, it is crucial to avoid redistribution or migration of the substances of interest within the sample, meaning that one should not induce a laterally extended liquid-phase mixing of matrix and analytes. Migration-free matrix preparation has so far been described only for lateral resolutions in the range of $30 \mu \mathrm{m}$ [31] and not for lateral resolutions of $1 \mu \mathrm{m}$. Solving the problems and limitations of matrix application will probably become the major tasks for the coming years in high-resolution scanning microprobe

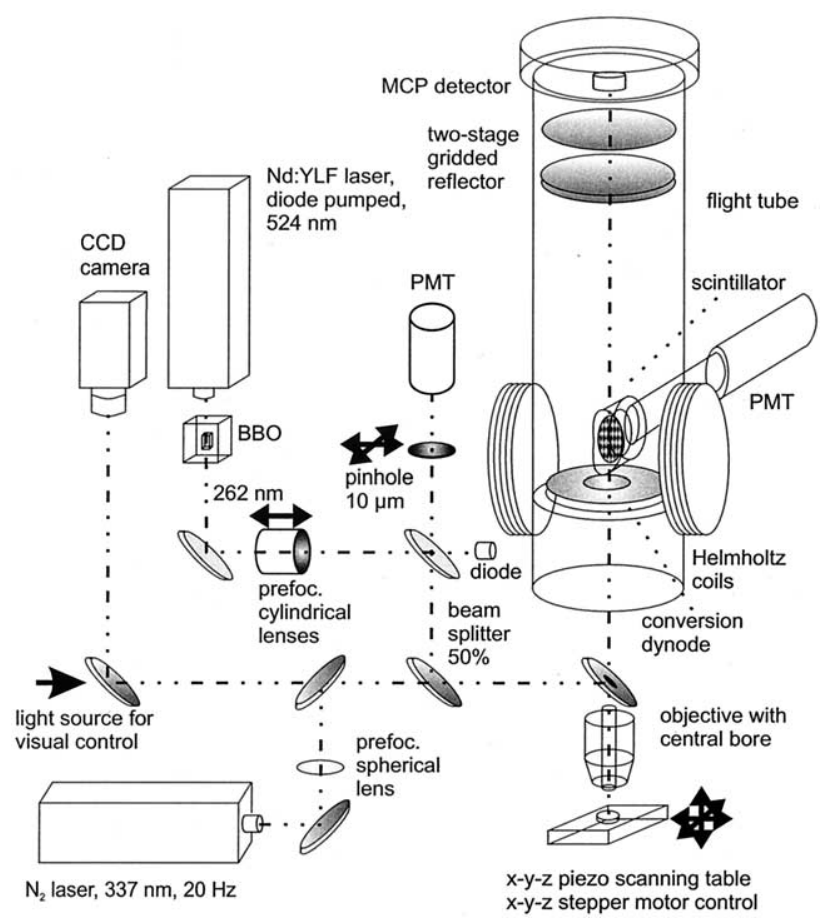

Figure 1. Scheme of the scanning LDI and MALDI reflectron time-of-flight mass spectrometer.

MALDI mass spectrometry. The current status and first achievements in this field will be described in a following publication. In this article the instrumental parameters are described and first experimental results achieved with our dedicated instrument are presented.

\section{Experimental}

A scheme of the instrument is shown in Figure 1. The imaging time-of-flight mass spectrometer is oriented in the vertical direction, providing for a horizontal plane for easy sample mounting.

The vacuum chamber is pumped by two $360 \mathrm{l} / \mathrm{s}$ turbomolecular pumps (Leybold AG, Cologne, Germany) which are mounted horizontally at the back of the sample chamber and in the middle of the flight tube, respectively. The forevacuum is provided by a $16 \mathrm{~m}^{3} / \mathrm{h}$ oil rotary pump (Leybold AG) which is located in a distant place with respect to the microscopical part of the instrument to avoid degradation of lateral resolution by vibrations. The working pressure of the instrument is about $5^{*} 10^{-7}$ mbar.

\section{UV Lasers}

Two different lasers can be used alternatively, both for desorption ionization and for confocal scanning laser microscopy, a frequency quadrupled $\mathrm{Nd}$ :YLF laser with $262 \mathrm{~nm}$ wavelength for optimized focusing conditions and highest lateral resolution, and an $\mathrm{N}_{2}$ laser with 337 $\mathrm{nm}$ wavelength for optimized MALDI conditions. 
Nd:YLF laser. The pulsed Nd:YLF laser model 421 QD (ADLAS, Luebeck, Germany,) is pumped by laser diodes. Laser light is frequency-doubled internally to reach output energies of $100 \mu \mathrm{J}$ per 15 ns pulse at 524 $\mathrm{nm}$. Frequency quadrupling is performed externally by a temperature-controlled BBO crystal (barium beta borate crystal for non-linear second harmonic generation). The final pulse energy is about $15 \mu \mathrm{J}$ at $262 \mathrm{~nm}$. Among the advantages of this diode pumped system are its high maximum repetition rate of $20 \mathrm{kHz}(8 \mathrm{kHz}$ at useful UV pulse energies), its low performance variations under change of repetition rates across the complete range of single shot to $8 \mathrm{kHz}$, and its small physical dimensions $(360 \times 90 \mathrm{~mm}$ laser head $)$. The output power of the laser can be controlled manually or by computer by adjusting the diode pump energy.

$\mathrm{N}_{2}$ laser. The nitrogen laser is a standard VSL 337 ND laser (Laser Science Inc., Cambridge, MA) as used in many commercial MALDI mass spectrometers. It provides for maximum pulse repetition rates of $20 \mathrm{~Hz}$ at pulse durations of $3 \mathrm{~ns}$. The output energy at $337 \mathrm{~nm}$ is $300 \mu \mathrm{J}$ per pulse.

\section{Laser Focusing}

Sub-micrometer focusing of the laser beam consists of a prefocusing part outside the vacuum and a final focusing part in the vacuum right above the sample manipulator. Both possible lasers are prefocused to about 10 $\mu \mathrm{m}$ focus diameter by suprasil quartz lenses. While the prefocused beam profile of the $\mathrm{N}_{2}$ laser is almost circular, the beam of the Nd:YLF laser is strongly elliptical in shape after quadrupling by the BBO crystal. A special optical correction is required in this case, in order to provide for a high numerical aperture at the entrance of the focusing objective lens. The ratio of the major and minor diameters of the ellipse is about 1:8. The beam, after prefocusing with a spherical lens, would thus fill a small stripe only on the entrance lens of the focusing objective. For this reason a special optical unit was developed for circularization, which prefocuses the two axes of the beam differently, as demonstrated in Figure 2.

The $x$ axis in Figure 2 (the minor axis) is focused by a short focal length $(f=5 \mathrm{~mm})$ cylindrical lens, while the $y$ axis (the major axis) is focused by a long focal length $(f=40 \mathrm{~mm})$ cylindrical lens. Both one-dimensional foci are adjusted to the same focal plane. The strongly elliptical beam profile is transformed into a circular beam profile by this procedure. The cylindrical lenses were bought from Melles Griot, Rochester, NY.

Final focusing is performed by a dedicated objective lens specially designed and manufactured for this setup. It consists of 5 suprasil quartz lenses (diameters between 35 and $50 \mathrm{~mm}$ ) for minimized spot size at 262 $\mathrm{nm}$ for axial laser beams. The objective has an o.d. of 90 $\mathrm{mm}$ and has a numerical aperture (N.A.) of 0.6 at a free working distance of $16 \mathrm{~mm}$. The long free working

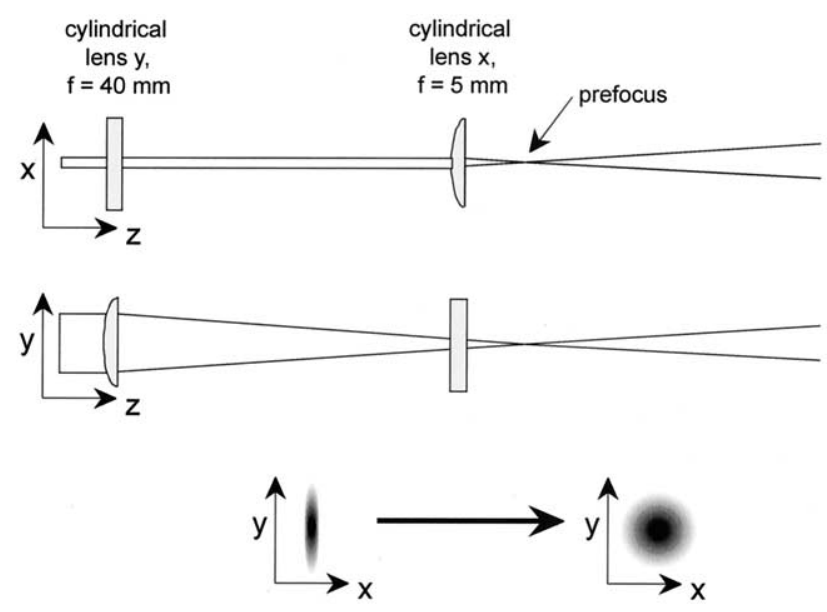

Figure 2. Cylindrical lens system for prefocusing and circularization of the elliptical beam of the frequency-quadrupled Nd:YLF laser.

distance is necessary for the mass spectrometrical setup to allow for placement of ion lens elements.

In order to allow ions to leave the ion source in a direction normal to the sample surface, the objective lens has a central hole which is fitted with a stainless steel tube of $6 \mathrm{~mm}$ inner diameter.

The theoretical limit of lateral resolution is [34]

$$
d=1.22 \cdot \frac{\lambda}{A}
$$

where $d$ is the diameter of the central disc of the diffraction pattern (= the "focus diameter"), $\lambda$ is the wavelength and $\mathrm{A}$ is the numerical aperture of the lens. With our setup at $262 \mathrm{~nm}$ laser wavelength and a numerical aperture of 0.6 , the minimal achievable laser focus diameter would thus be $0.53 \mu \mathrm{m}$. The mass spectrometric lateral resolution, i.e., the diameter of a surface disc from which analytical information is extracted, should be identical or very similar to the focus diameter. Due to the strong non-linearity of the desorption process, however, the practical lateral resolution can be higher or considerably lower than the focus diameter, depending on the laser irradiance used and assuming a near-gaussian intensity profile $[1,3]$.

The practical optical lateral resolution can be higher than described by eq 1 , taking into account that structures can still be optically resolved even if the diffraction discs of two objects overlap to a certain extent. This effect is usually described by the physiological factor $k \geq 1$ [34], so that

$$
d=1.22 \cdot \frac{\lambda}{k \cdot A}
$$

where $d$ now is the smallest size of resolvable objects.

The optical quality of the lens has been tested on an optical bench outside the vacuum. Figure 3 shows the intensity distribution in the focus of the lens at $266 \mathrm{~nm}$ 


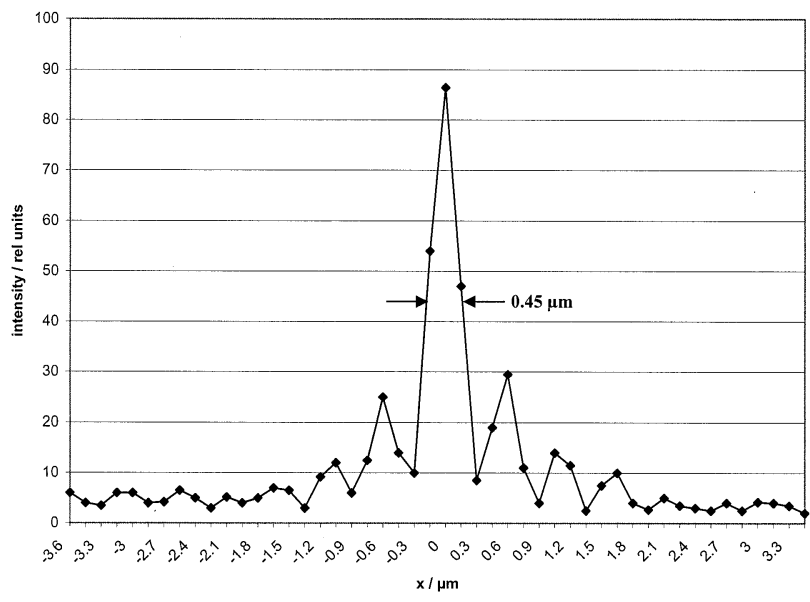

Figure 3. Intensity distribution of the focused Nd:YLF laser beam (frequency quadrupled to $262 \mathrm{~nm}$ wavelength) after $100 \times$ magnification as measured by a diode array with diode spacings of $15 \mu \mathrm{m}$. Each data point corresponds to the light intensity measured by a single diode. The determined focus diameter is 0.45 $\mu \mathrm{m}+/-0.15 \mu \mathrm{m}$.

as measured by a diode array detector after $100 \times$ magnification by a microscopic objective lens (Leitz ultrafluar 100, N.A. 0.85 in air). The diodes are $15 \mu \mathrm{m}$ apart. The measured focus diameter at $262 \mathrm{~nm}$ (= diameter of the first minimum of the diffraction pattern) is thus $0.45 \mu \mathrm{m}+/-0.15 \mu \mathrm{m}$.

The optical setup for $337 \mathrm{~nm}$, using the nitrogen laser, was tested by microscopic investigation of burn patterns of the focused laser beam on thin films of dye coated by a felt tip pen onto a standard aluminum sample holder. Burn patterns were created under vacuum conditions and under mass spectrometrical control. At the irradiance threshold for detection of ions, no burn patterns could be observed optically. At twofold to threefold threshold irradiance, circular holes of 0.6 to $0.7 \mu \mathrm{m}$ diameter could be observed after single-shot laser desorption with a high-quality optical microscope (Olympus BX 40), as shown in Figure 4. As expected from the near-gaussian intensity profile, the diameter of the burn holes increased markedly with increasing irradiance. It can therefore be assumed that at threshold irradiance the analytical diameter of the desorption region is even lower than $0.6 \mu \mathrm{m}$ with this setup at 337 nm.

\section{Sample Scanning}

Since high optical resolution can be achieved only for an axial beam path with the chosen setup, a fixed optical system is mandatory. Sample scanning can thus not be performed the usual way by scanning the laser beam across the sample, but has to be performed by moving the sample under the laser focus. This is done by a fast piezo-driven nanostage (Graf Mikrotechnik, Wertingen, Germany), which is mounted on a stepper-motor driven $x$-y-z-stage for sample positioning. With this arrangement samples can be positioned within an area of

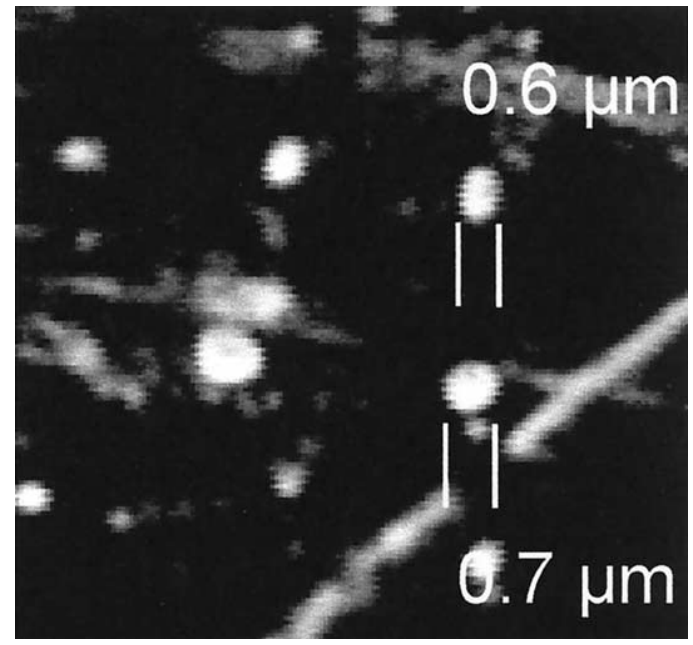

Figure 4. Laser burn patterns after single-shot irradiation at twofold to threefold threshold irrandiance, acquired at $337 \mathrm{~nm}$ nitrogen-laser wavelength on red felt tip dye.

$20 \times 20 \times 20 \mathrm{~mm}$, and areas of $100 \times 100 \mu \mathrm{m}$ can be scanned with a maximum resolution of $0.25 \mu \mathrm{m}$. In the high-speed mode of the piezo stage the sample load is limited to a maximum mass of $2 \mathrm{~g}$, allowing us to scan the 160,000 pixels of the target area within less than $2 \mathrm{~s}$. The piezo stage is controlled by a Motorola 68000 (Motorola Inc., Schaumburg, IL) microprocessor system. The stepper motors are located inside the vacuum and are controlled by a stepper motor controller via a joystick or computer.

\section{Confocal Microscopy}

The same laser and beam path as for desorption ionization is used with decreased pulse intensities for optical, confocal laser scanning microscopy (CLSM). Pulsed UV light at $262 \mathrm{~nm}$ is focused onto a certain pixel of the sample under investigation (see Figure 1). Reflected light from the sample pixel takes the identical beam path back through the lens and partly passes the 50\% transmission beam splitter. At the same position as the prefocus of the incoming laser beam, on the one hand, and at a corresponding position behind the beam splitter on the other hand, the reflected light from the surface is focused. An aperture $10 \mu \mathrm{m}$ in diameter is located at this position to allow reflected light to reach a photomultiplier tube (PMT) behind the aperture. Any light from sources other than the focused sample pixel is unable to pass the aperture with significant intensity and is thus not detected. The photomultiplier signal is processed by a box car averager and acquired by a $200 \mathrm{kHz} 12$ bit A/D converter. The box car averager integrates the light intensity within a predefined time window. The actual position of the scanning stage is determined by a noncontacting displacement measuring system KDM-8200 (Kaman Instrumentation Corporation, Colorado Springs, CO), which is used for feedback control of the piezo system. The sensor signal is 
acquired by a second channel of the A/D converter. The intensity value is correlated with the pixel position and is used by the computer to form an optical twodimensional $b / w$ image of the sample. A complete image of $100 \times 100 \mu \mathrm{m}$ acquired with a pixel resolution of $0.25 \mu \mathrm{m}(160,000$ pixels) is formed on the computer screen within 30 seconds.

\section{Video Imaging}

For overview observation the sample can be imaged by standard light microscopy with a magnification of about 400 . An area of about $500 \times 400 \mu \mathrm{m}$ is displayed on a video monitor. The sample is illuminated and observed not from the side but through the objective lens because of geometrical constraints. Since the lens is not corrected for chromatic abberation, only monochromatic light can be used for sample imaging. A He-Ne laser with an output energy of $15 \mathrm{~mW}$ is used for sample illumination. Coherent light is usually unusable for illumination of surfaces having topological modulations in the range of the laser wavelength because of the formation of speckle interferences, considerably deteriorating the visibility. The He-Ne laser beam can thus not be used directly for microscopic illumination but has to be processed first. This is done by feeding the beam into a quartz fiber of $3 \mathrm{~m}$ length and shaking the fiber by a vibrating motor. This procedure leads to sufficient time-dependent distorsion of the mode structure of the beam for a homogeneously averaged light intensity distribution to be obtained on the sample.

Due to the longer wavelength of the He-Ne laser (633 nm) compared to the UV laser $(262 \mathrm{~nm}$ or $337 \mathrm{~nm}$, resp.) the focal length of the objective lens is considerably longer for the video imaging beam path. A correction lens is thus used leading to a final distance between objective lens and video camera of $800 \mathrm{~mm}$.

The video image is observed on $a b / w$ monitor or displayed on the computer screen by a video overlay card, allowing acquisition and storage of video images on the computer hard disk.

\section{Mass Analysis}

Ions formed by the desorption/ionization laser are accelerated to $10 \mathrm{keV}$ and collimated by electrostatic elements located in front of the objective lens. The ion beam is steered through the stainless steel tube in the center of the lens by adjusting the potentials of the elements.

In the linear mode, ions pass the field free drift tube and hit the microchannel plate detector at the top end of the instrument. The instrument is equipped with an ion reflector for flight time compensation of ions having kinetic energy deviations from the ion source. In the reflectron mode ions are decelerated and reflected coaxially in a two-stage gridded reflector.

\section{Ion Detection}

Reflected ions are postaccelerated onto an annular copper-beryllium conversion plate at $-7 \mathrm{kV}$. Secondary electrons desorbed from the conversion surface are accelerated to $7 \mathrm{keV}$ and are deflected $90^{\circ}$ by a magnetic field. After postacceleration to $9 \mathrm{keV}$ they hit a plastic scintillator plate which is mounted on a vacuum window. Outside the vacuum a photomultiplier tube detects the converted ion signal. This arrangement avoids high-cost annular channelplate detectors and takes advantage of the stability of maintenance-free photomultipliers. Instead of the scintillator/photomultiplier setup, a microchannel plate detector was used alternatively with comparable performance for detection of secondary electrons after ion conversion.

\section{Data Acquisition}

The ion signal from the photomultiplier is split and fed into a dual channel preamplifier connected to a dual channel transient recorder card model PAD82 (Spectrum Systementwicklung $\mathrm{GmbH}$, Siek, Germany). The signal is digitized using two channels of 8 bit dynamic range at different sensitivity settings. From the two channels a combined spectrum with enhanced dynamic range is composed by the data acquisition program. For each data point a virtual 16 bit memory area is filled by either one of the two channels depending on the signal intensity at that data point. The system can be operated alternatively with only 8 bit dynamic range by using just one channel.

Mass spectra can be processed and stored individually, as in regular laser desorption mass spectrometry, or can be used to calculate two-dimensional ion images by transforming signal intensities of certain mass peaks into gray-scale pixel values. Depending on the memory depth of the acquired spectra (i.e., the acquired mass range) more than 50 spectra per s can be processed with a standard computer. This leads to acquisition times in the range of 4 to $15 \mathrm{~min}$ for $100 \times 100 \mu \mathrm{m}$ ion images at $1 \mu \mathrm{m}$ pixel resolution. For each of the processed mass peaks an image file is stored to disk in TIF file format. These image files can be handled later by common image processing programs. Home-built software (ULISSES version 8.0, Bernhard Spengler copyright (1985-2002) was employed for all operations of instrument control, data acquisition and data evaluation.

\section{Results and Discussion}

The general system capabilities are demonstrated in the following.

\section{Confocal Microscopy}

Figure 5 is a confocal image of a $100 \times 100 \mu \mathrm{m}$ area of a lithographical object commonly used for testing electron microscopes (PLANO W. Plannet GmbH, Mar- 


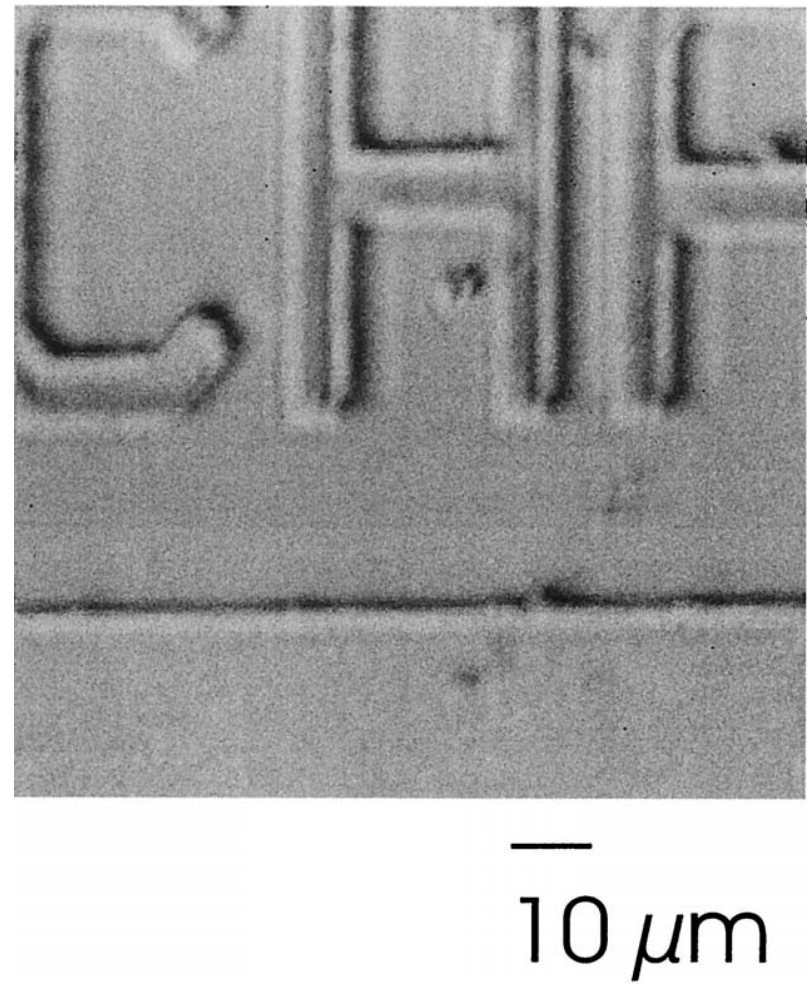

Figure 5. UV confocal laser scanning microscopy (UV-CLSM) reflected light image of a lithographical test object acquired at 262 $\mathrm{nm}$ laser wavelength. A large pinhole aperture of $30 \mu \mathrm{m}$ in diameter was used in front of the photomultiplier in order to increase the focal depth and thus reduce vertical (three-dimensional) discrimination.

burg, Germany). The sample is a $4.5 \times 4.5 \mathrm{~mm}$ silicon wafer, covered with a $0.5 \mu \mathrm{m}$ thick layer of $\mathrm{SiO}_{2}$ and a $0.5 \mu \mathrm{m}$ thick layer of aluminum on top. Structures are patterned onto the chip by electron beam direct writing and dry etching. The image shows an area of $100 \times$ $100 \mu \mathrm{m}$ of this sample scanned with steps of $0.25 \mu \mathrm{m}$ at $262 \mathrm{~nm}$ wavelength of the Nd:YLF laser. The area contains elevated letters of $0.5 \mu \mathrm{m}$ aluminum within an etched area of silicon. The lower part of the image shows the rim of the non-etched (elevated) aluminum surface. A strong surface contrast (shadow formation) and almost no absorption contrast is obtained. This is due to the fact that the spectral absorption is similar for aluminum and silicon in UV light. Under visible light observation, on the other hand, aluminum areas appear white, while silicon areas appear almost black. Shadow formation was enhanced in Figure 5 by aligning the beam path for optical confocal microscopy slightly off-axis. The (virtual) light source in this image is in the lower left corner.

The confocal image of Figure 5 was acquired with a rather large photomultiplier aperture of $30 \mu \mathrm{m}$. Smaller apertures down to $10 \mu \mathrm{m}$ have been used as well, enhancing the optical resolution in $\mathrm{x}, \mathrm{y}$, and $\mathrm{z}$ direction. With our current data system, however, the smallaperture images are more complicated to evaluate, because of the extremely low focal depth of less than
$1 \mu \mathrm{m}$ under these conditions. Since all off-focus areas appear black in confocal microscopy, a complete image of a sample with surface topologies above the focal depth can only be acquired by averaging (or threedimensional processing) multiple scans at different focal positions. Three-dimensional processing has not been implemented in our data system yet. Using a $30 \mu \mathrm{m}$ aperture deteriorates lateral resolution to about $2 \mu \mathrm{m}$ but allows us to acquire realistical images with just a single scan.

\section{Ion Images}

Figure 6a shows a confocal image acquired at $262 \mathrm{~nm}$ of another area of the test sample characterized by four etched lines, a mechanically scratched area in the right part and a dark spot in the center. The aperture used had a diameter of $30 \mu \mathrm{m}$. As in Figure 5 the optical beam path was aligned off-axis resulting in a virtual light source in the lower left corner. The small lines in Figure 6a are thus not elevations (non-etched aluminum) but indentations (silicon substrate).

The corresponding pixel-identical ion image of the same area is shown in Figure $6 \mathrm{~b}$ for the $\mathrm{m} / \mathrm{z}=28 \mathrm{u}$ signal of silicon. The image has been scanned with 0.5 $\mu \mathrm{m}$ per pixel. It indicates a mean line width of 2 pixels $(1 \mu \mathrm{m})$ which is in good agreement with the control values given for the test object. In the area of the dark spot an irregular distribution of silicon is observed.

\section{Surface Destruction}

Laser desorption ionization is by nature a destructive technique. After laser irradiation and ion formation the surface is deformed by ablation of a volume of about $1 \mu \mathrm{m}^{3}$ per pixel per laser pulse. This value of ablated volume has not been investigated systematically so far but is approximated from earlier investigations on laser microprobe mass analysis, laser desorption ionization, and MALDI mass analysis [3, 11, 35]. In ordinary MALDI or LDI mass spectrometry employing spot sizes in the range of 50 to $200 \mu \mathrm{m}$ in diameter, this ablated volume is spread over a large desorption area leading to (unobservable) ablation depths in the low nanometer range. In laser microprobing, however, the same ablation volume leads to ablation crater depths in the micrometer range. Since the confocal optical mode is very sensitive with respect to surface topology, the ablation effect can be visualized by confocal optical imaging of the sample area before and after mass spectrometric scanning. Optical scanning itself is, due to the lower irradiance, non-destructive and can be performed many times without causing any visible surface effect. Figure $7 \mathrm{a}$ and $\mathrm{b}$ show the same area of the test sample before and after MS (high-irradiance) scanning at $262 \mathrm{~nm}$. The surface is strongly affected by formation of desorption craters. Figure $7 \mathrm{c}$ shows the scanned area slightly shifted in order to demonstrate the effect at the edges of the scanned area. 


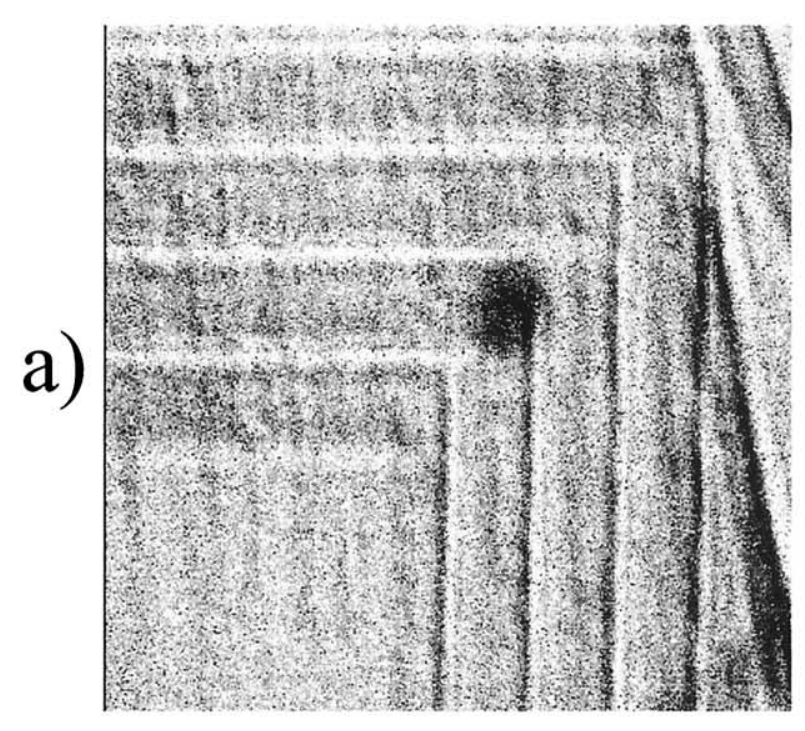

\section{$10 \mu \mathrm{m}$}
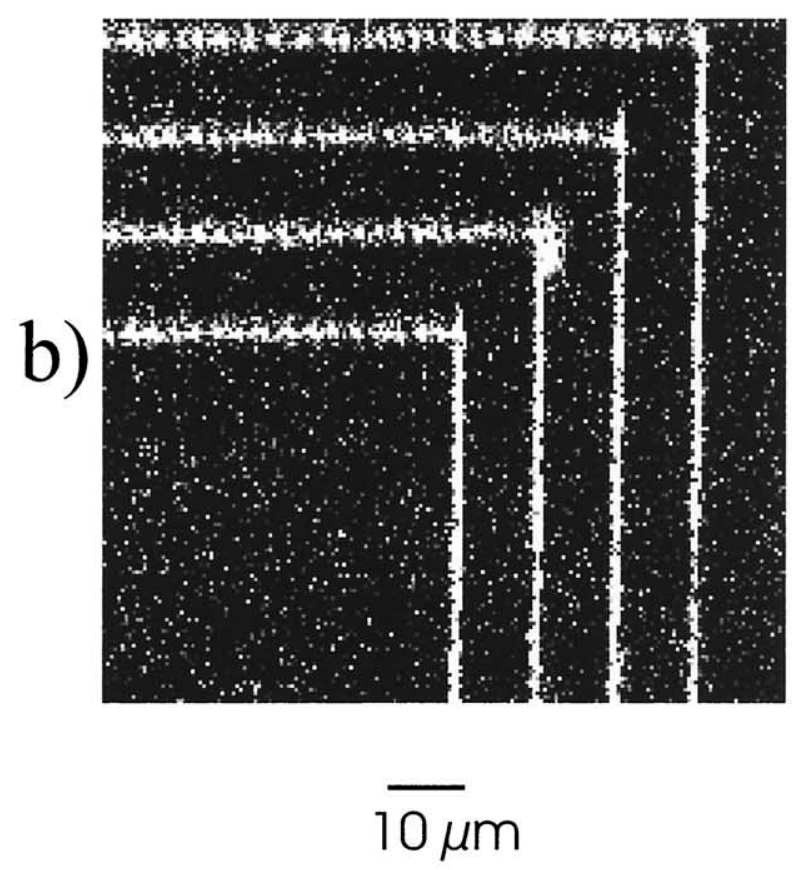

Figure 6. (a) UV confocal laser scanning microscopy (UV-CLSM) image of a lithographical test sample acquired at $262 \mathrm{~nm}$ laser wavelength and a pinhole aperture diameter of $10 \mu \mathrm{m}$. The sample is a silicon wafer covered with $0.5 \mu \mathrm{m} \mathrm{SiO}$ and $0.5 \mu \mathrm{m} \mathrm{Al}$. The imaged area is $100 \times 100 \mu \mathrm{m}$. The illuminating laser beam path is set slightly off-axis in order to enhance the surface (topological) contrast, resulting in a virtual light source positioned in the lower left corner of the image. (b) Scanning laser desorption ionization mass spectrometrical image of the same area as imaged in (a) and acquired at $262 \mathrm{~nm}$ laser desorption wavelength. The mass signal of silicon $(m=28 \mathrm{u})$ was used for imaging. White pixels correspond to high signal intensities of silicon ions, dark pixels correspond to low signal intensities.

As mentioned above, confocal optical imaging is very sensitive to surface topology. Imaging of surface modifications after MS scanning is therefore enhanced by confocal imaging. The destruction of analytical information by desorption scanning is much less pronounced, as demonstrated later in Figure 11. Several images from the same area can be obtained with only slight modification of the signal.

\section{Surface Analysis}

Imaging of the surface distribution of different substances with high lateral resolution is demonstrated in Figure 8 . The sample was prepared by depositing thin layers of dye with two felt tip pens onto a flat aluminum target. The target was first covered completely with dye from the red felt tip pen. After drying, the coating was partially overlayed with dye from the green felt tip pen. The edge of the green overlay was imaged mass spectrometrically with $262 \mathrm{~nm}$ desorption wavelength using the signals of $m / z=122 \mathrm{u}$, indicative of the red dye, and $m / z=372 \mathbf{u}$, indicative of the green dye. An area of $100 \times 100 \mu \mathrm{m}$ was scanned with a pixel (step) size of $0.5 \mu \mathrm{m}$. The resulting two grey scale images for the red and the green dye were transformed into one composite image by using the red channel of an RGB color image for the red-dye image and the green channel for the green-dye image. The blue channel was left empty. The resulting color image in Figure 8 shows pure red intensities for all pixels, where only the signal of the red dye was observed $(\mathrm{m} / z=122 \mathrm{u})$, and pure green intensities for all pixels, where only the signal of the green dye was observed $(\mathrm{m} / \mathrm{z}=372 \mathrm{u})$. Only few pixels are colored in yellow, indicating that ions from red and green dye were detected. This indicates that with the first scan of a multi-layer sample only the top layer is imaged (and desorbed), while the deeper layers are still covered.

The image shown in Figure 8 demonstrates that surface analysis with effective lateral resolution in the $0.5 \mu \mathrm{m}$ range is possible with our setup, indicated by crosstalk-free, sharp edges between red and green areas.

The image was acquired with two laser irradiance settings to demonstrate the influence of irradiance on image characteristics. As can be seen the noise level is higher at lower irradiance, but more information on surface topology can be extracted from signal variations in images acquired at lower irradiance.

\section{Biological Samples}

Figure 9 shows mass spectrometric images of a pine tree root. The sample was provided by W. H. Schroeder at the Forschungszentrum Juelich, Germany, and was prepared by embedding the root in an epoxy resin. A flat surface of the bulk sample was created by means of a glass knife and investigated by MS scanning. Ion signals of potassium and calcium were imaged (white $=$ high, black $=$ low intensity) in a cross section of the root. The size of the total image is $100 \times 100 \mu \mathrm{m}$. The 

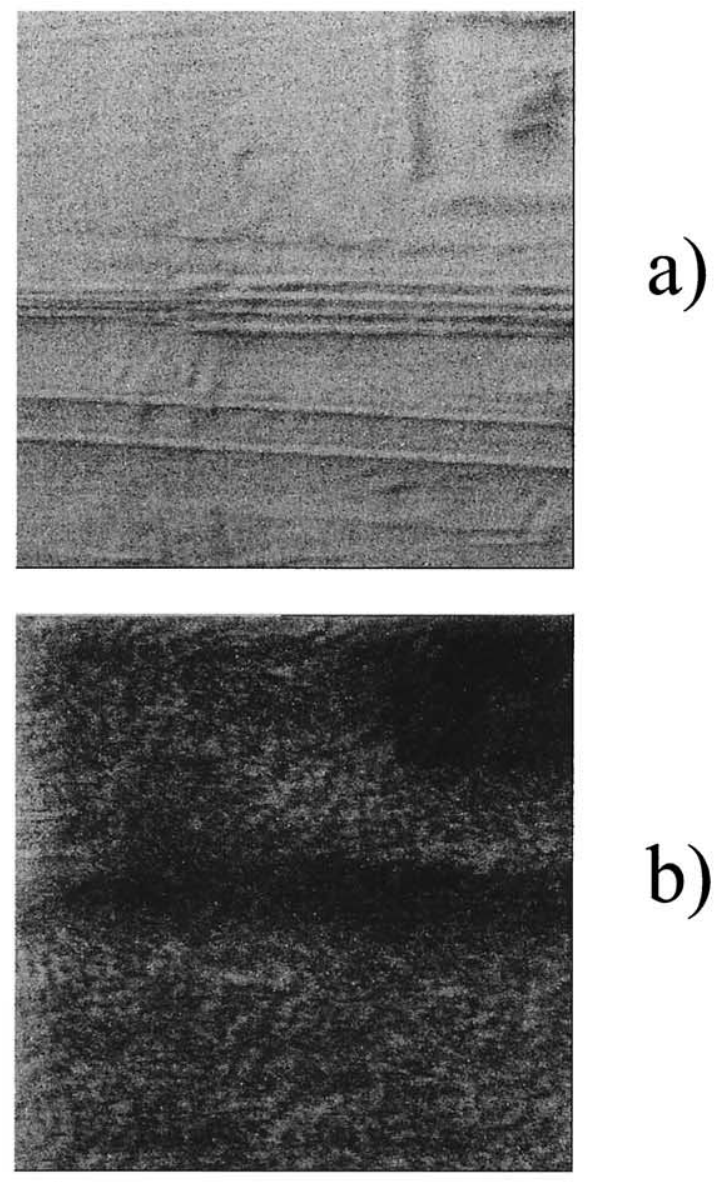

b)

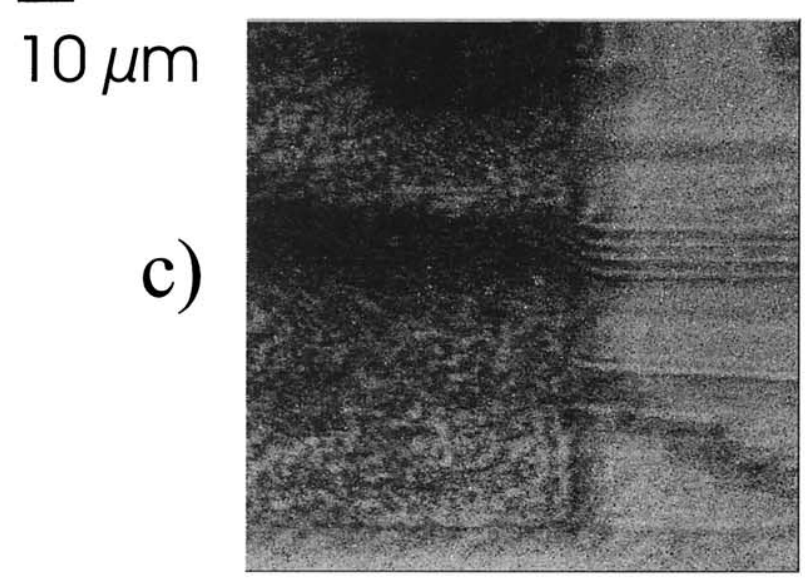

Figure 7. (a) UV-CLSM image of a selected area of the lithographical test sample acquired at $262 \mathrm{~nm}$ laser wavelength prior to LDI-MS imaging. The illuminating laser beam path is set slightly off-axis in order to enhance the surface (topological) contrast. (b) UV-CLSM image of the same area as in (a) after LDI-MS imaging. Ablation of material strongly distorts the surface topology resulting in visible effects in the surface contrast image. (c) UV-CLSM image of an area shifted versus the position used in (a) and (b) after LDI-MS imaging.

images were scanned with lateral increments of $0.25 \mu \mathrm{m}$. Structures of the cell walls are clearly imaged and show the expected high concentration of potassium and calcium in these areas [4].

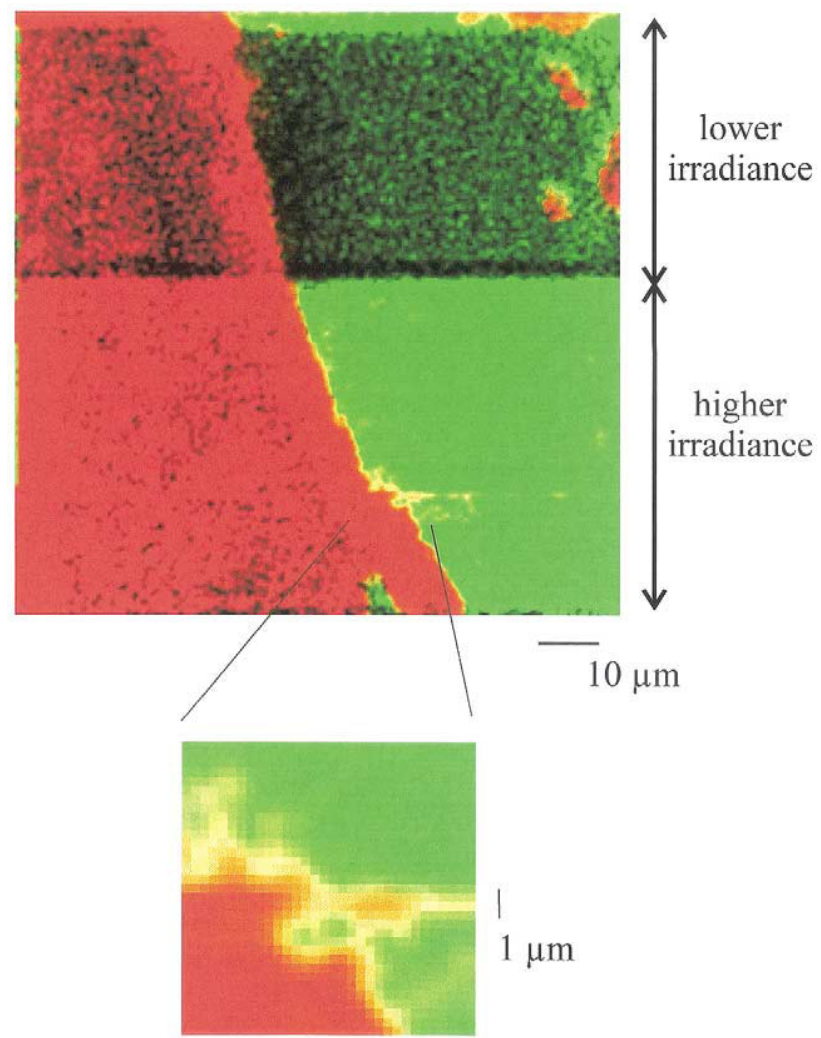

Figure 8. Scanning laser desorption ionization mass spectrometric image of an aluminum target covered with red felt tip pen dye and partly overlayed with green felt tip pen dye. The image was observed at $262 \mathrm{~nm}$ laser wavelength with a scanning step size of $0.5 \mu \mathrm{m}$ and one laser shot per pixel. Mass signal intensities from the red dye $(m / z=122 \mathrm{u})$ are coded in red, those from the green dye $(m / z=372 \mathbf{u})$ are coded in green. Yellow pixels indicate detection of ions from both dyes in the same spectrum. The total scanned area is $100 \times 100 \mu \mathrm{m}$ (top image). The size of the magnified section is $10 \times 10 \mu \mathrm{m}$ (bottom image).

\section{SMALDI Mass Analysis of Peptide Samples}

As a demonstration of Scanning Microprobe MALDI imaging on the micrometer scale (SMALDI mass spectrometry), Figure 10 shows the distributions of the peptide substance $\mathrm{P}\left([\mathrm{M}+\mathrm{H}]^{+}=1348 \mathrm{u}\right)$, of the matrix 2,5-dihydroxybenzoic acid (DHB, $m / z=154 \mathrm{u}$ used as marker signal) and of potassium $(m / z=39 u)$ in a regular MALDI dried droplet preparation of an aqueous solution of these compounds. The matrix was prepared in high concentration $\left(6^{*} 10^{-2}\right.$ molar) while the analyte (substance P) was added in $10^{-5}$ molar concentration. Potassium was present as contaminant only. The sample is typical of standard preparations in MALDI mass spectrometry of peptides in biochemical analysis. It was investigated by laser microprobing to clarify preparational mechanisms, which are known to be important for successful analysis of biological macromolecules. The images were acquired from the rim of the dried droplet, known to be characterized by formation of large matrix crystals in this preparation method [14]. The top left of the images is part of the flat inner area of the dried droplet, formed by very small matrix 


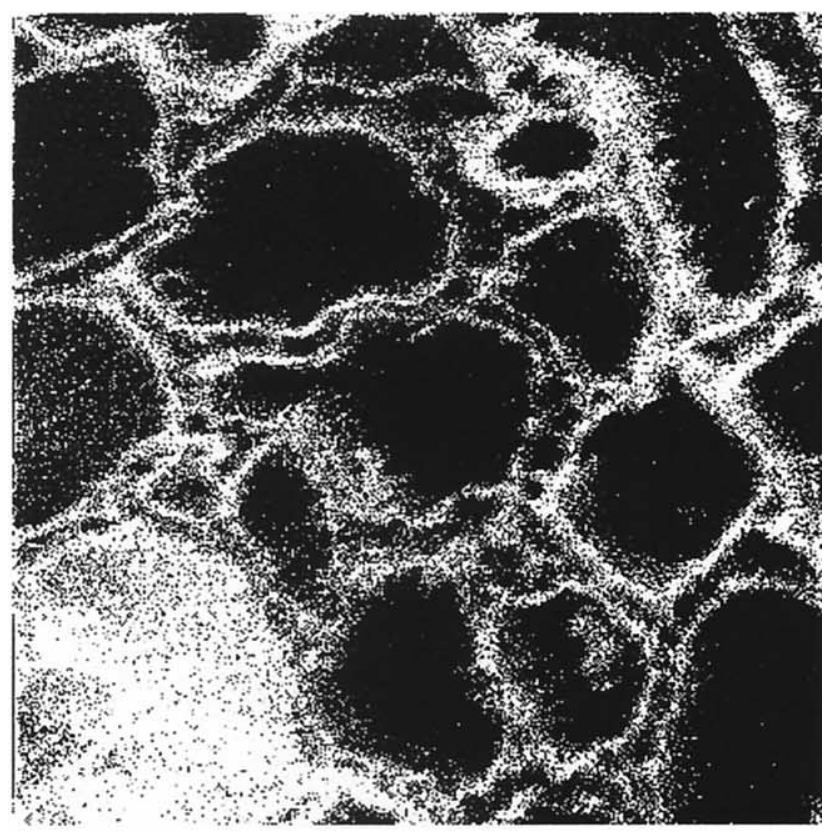

\section{Potassium}

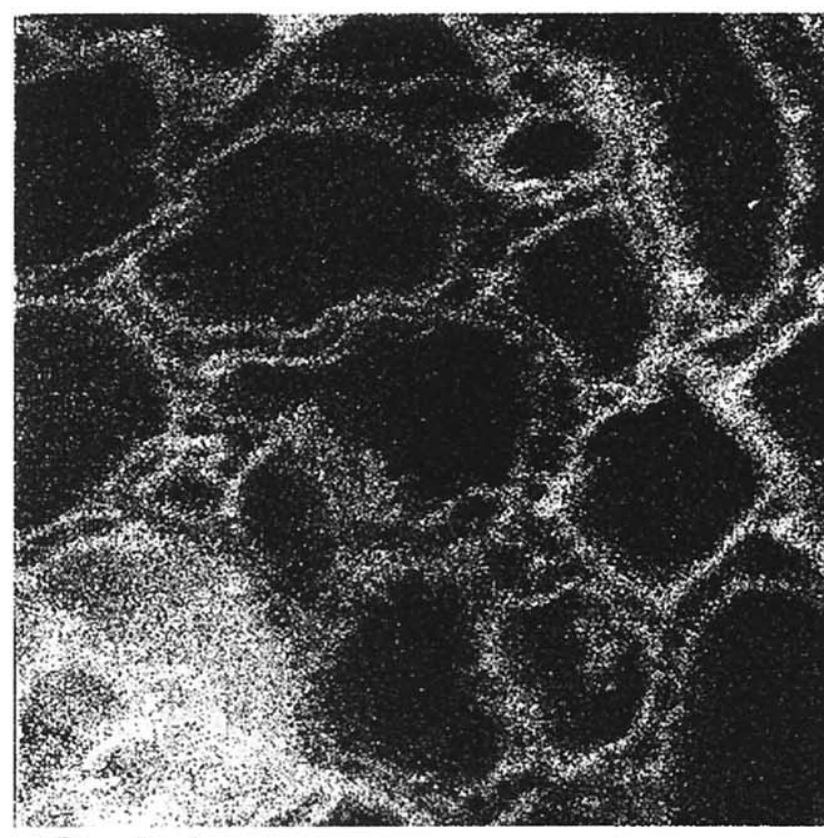

\section{Calcium}

Figure 9. Scanning laser desorption/ionization mass spectrometrical image of a pine tree root, acquired at $262 \mathrm{~nm}$ wavelength. The image was scanned with a step size of $0.25 \mu \mathrm{m}$. High ion signal intensities of potassium/calcium are coded in white, low intensities are coded in black.

crystals. An overview of the sample is shown in the microscopical image acquired with lower magnification. The inclusion of analyte molecules (substance P in this case) into the growing crystals during the drying process of the droplet, as well as the exclusion of alkali ions has been discussed as a crucial step in successful MALDI analysis [17, 36, 37]. The top row of Figure 10 shows the analyte ion signal, which apparently closely images the physical structure of the matrix crystals.

In Figure 10 from left to right, the first four scans (one laser shot per pixel per scan) are displayed. After a few laser shots per pixel a hole is drilled into the matrix crystal. Matrix ion signals (second row) are obtained from the inner area and from the large crystals of the sample, but degrade considerably after the first scan. Loss of the matrix signal from the nanocrystalline inner area is probably due to the fact that the sample is already ablated after one highly focused laser pulse per pixel (see discussion of Figure 7). Loss of the matrix signals from the larger matrix crystals, on the other hand, is believed to result from charge exchange processes in the gas phase between (in this case) rare protonated matrix molecular ions and relatively abundant neutral analyte molecules. Ions of matrix molecules are lost because of the formation of ions of analyte molecules which have a higher proton affinity than the matrix molecules. Such effects, including neutralization and signal loss of matrix ions have been observed and discussed earlier [38]. Observation of low-intensity matrix ion signals is in accordance with optimized desorption conditions in high ion transmission instruments.

The sequence of four consecutive scans supports the idea of inclusion of analyte into matrix crystals. Intense analyte ion signals are obtained not only from the surface of matrix crystals (first shot) but also from inside the crystals (second to fourth shots). No considerable differences in ion intensities are observed between the first scan and consecutive scans. Analyte distributions in MALDI samples were investigated earlier by confocal fluorescence microscopic imaging [39] and are confirmed by our investigations. With our method, however, information not only on the analyte distribution in the sample but additionally on the microscopically resolved origin of desorbed analyte ions, i.e., the laterally and axially (depth) resolved ion yield, is accessible.

The bottom row (Figure 10) shows potassium ion intensities which obviously stem mainly from areas outside the matrix crystals. The images of potassium are almost perfectly inverted relative to the images of the analyte, strongly supporting the idea that peptides (and proteins) are necessarily incorporated into the growing matrix crystals upon sample preparation for a successful MALDI analysis, while salt contaminants are not incorporated and thus do not hinder the analyte ion formation process. The lateral distribution of potassium and substance $\mathrm{P}$ in the ion images is shown in more detail in another composite image (Figure 11a), coding the potassium signal with the green RGB channel and the analyte signal with the red channel. It is clearly seen that only very few pixels have yellow color, indicating the detection of both potassium and analyte ions at the same time. This behavior is even more pronounced after several scans. Figure $11 \mathrm{~b}$ is a composite image of the 

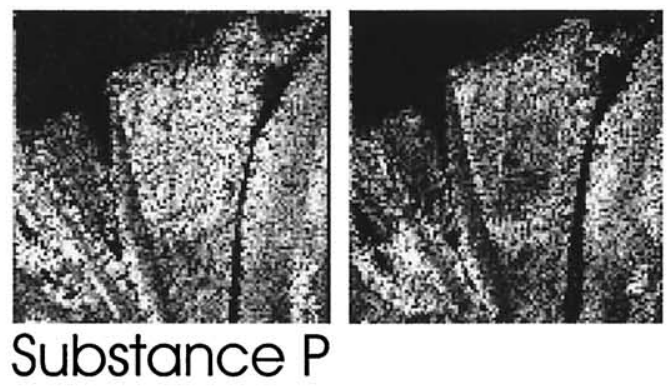
Substance P
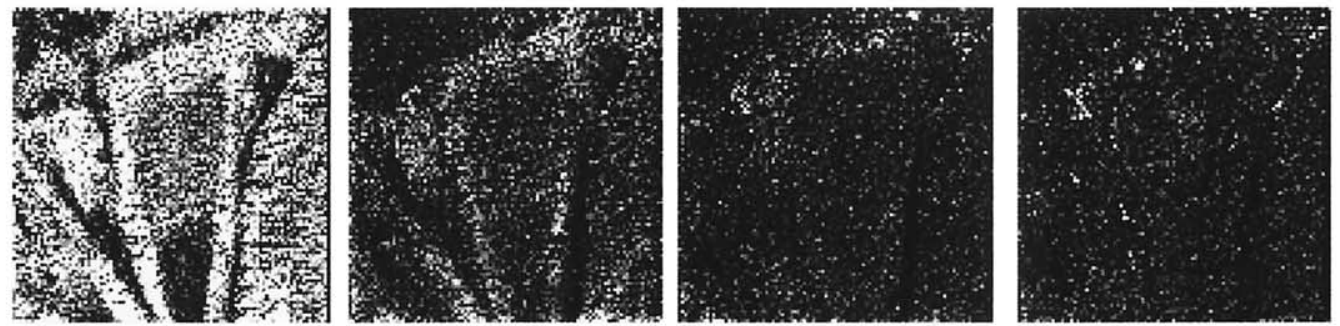

DHB
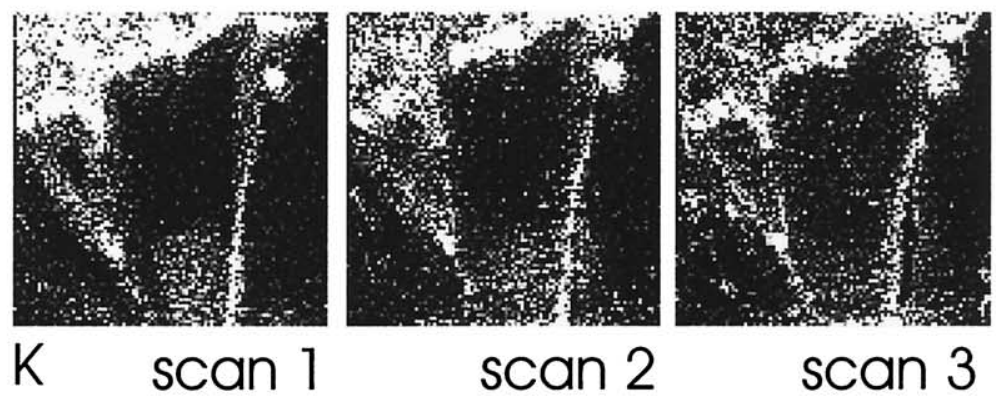

scan 2

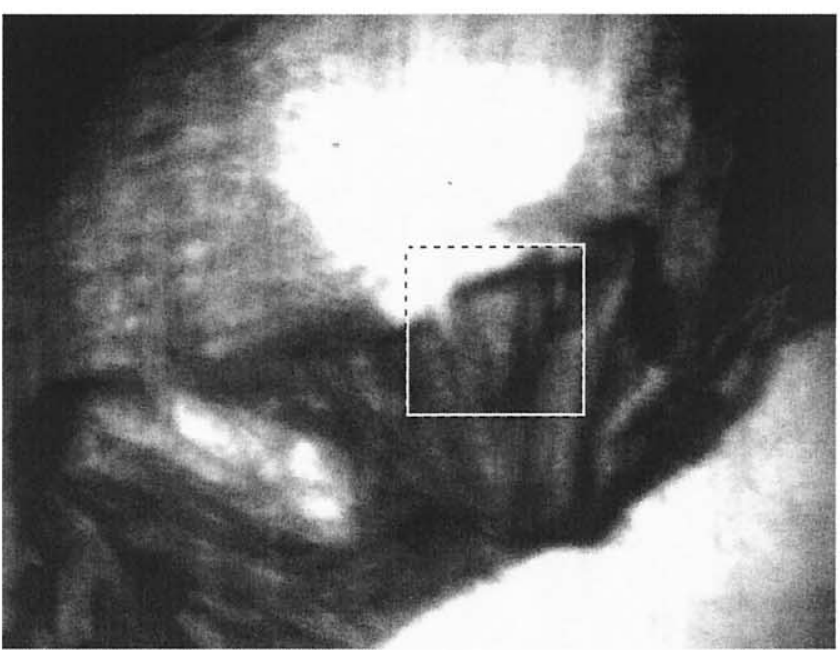

\section{Optical image (CCD camera), visible light}

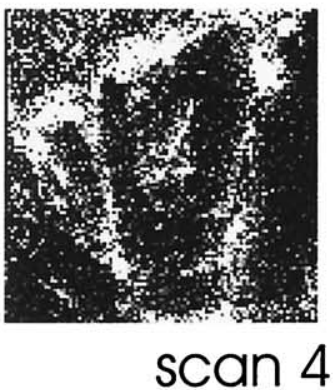

Figure 10. Scanning microprobe matrix-assisted laser desorption/ionization (SMALDI) mass spectrometrical image of a regular MALDI sample preparation of the peptide substance $\mathrm{P}$ in 2,5dihydroxybenzoic acid (DHB) matrix on a flat aluminum target. The image was scanned with $1 \mu \mathrm{m}$ step size at $262 \mathrm{~nm}$ laser wavelength and one laser shot per pixel. Laser irradiance was just above threshold for ion detection. See text for further explanation.

fifth scan, showing the strongly degraded matrix crystal with far fewer yellow pixels, compared to the first scan in Figure 10. This observation can be explained the following way. It can be assumed that the dried-droplet prepared sample is characterized by formation of larger matrix crystals which are covered by a thin layer of very small nanocrystals formed from the drying solution. The first scan can therefore be taken as an overlay of 

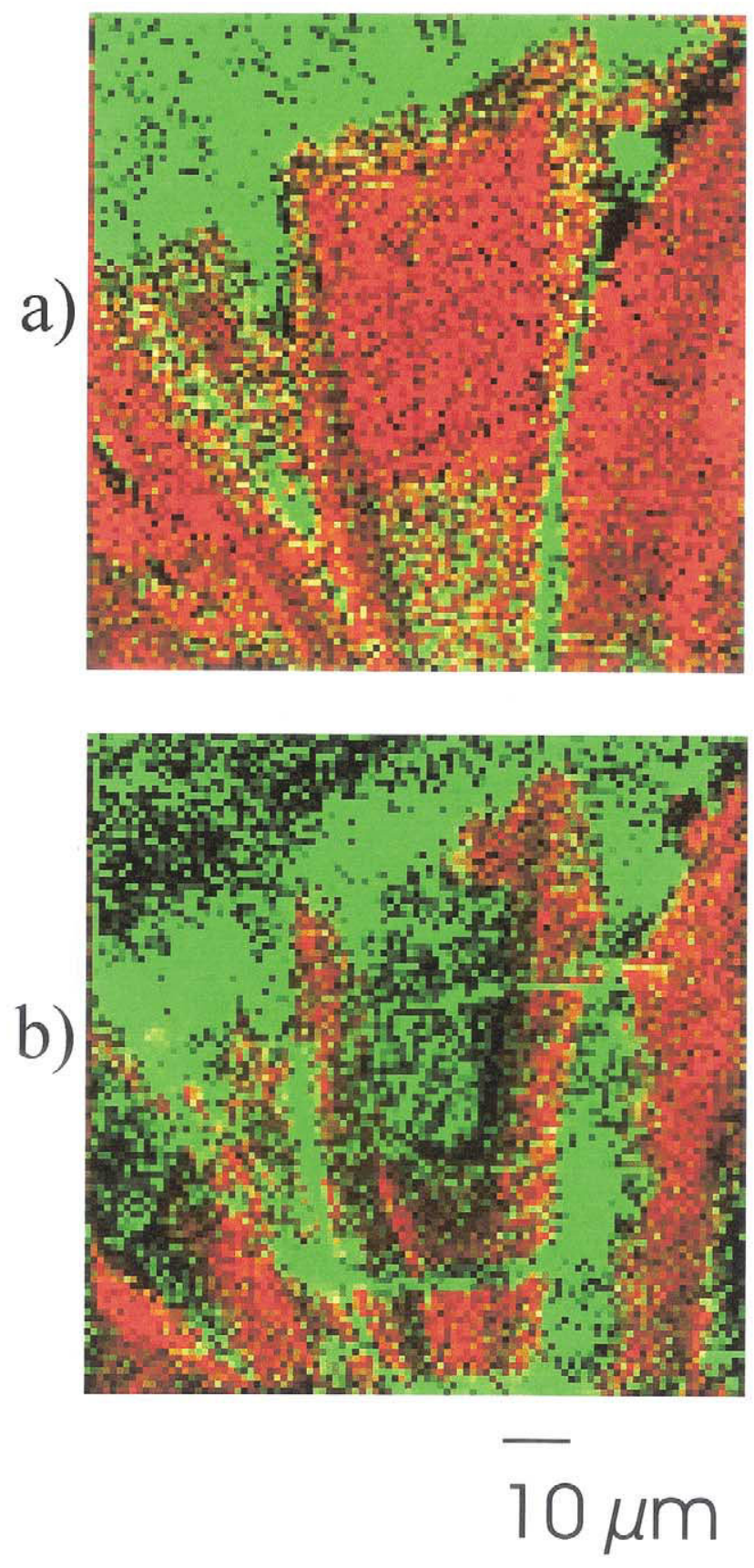

Figure 11. (a) Overlay image of lateral distributions of potassium and substance P from Figure 11 (first scan). Potassium ion signals are coded in green, substance $\mathrm{P}$ ion signals are coded in red. Yellow pixels indicate detection of ion signals from potassium and substance $\mathrm{P}$ in the same spectrum. (b) Overlay image as (a), but from the fifth scan (fifth laser shot per pixel). See text for further explanation.

large-crystal and nano-crystal imaging, supported by observation of a higher noise level in the first scan (data not shown here). Even with highly resolved scanning at $0.5 \mu \mathrm{m}$ focus size one can, to some extent, still detect ions from different areas in parallel, analyte-doped matrix crystals and salt crystals. After the first scan the nano-crystal layer is ablated and the detection of salt and analyte in parallel is less pronounced. Segregation of cationization agents from the matrix crystals was observed by TOF-SIMS earlier [40], but since analyte ions are not detected in the SIMS experiments, the results cannot be correlated to the actual analyte distribution and to analyte ion formation.

This strong mutual exclusion has been observed for several peptide samples investigated so far with submicrometer resolution. It is not observed after defocusing the laser beam, i.e., in a common MALDI mass spectrometer. This is because a typical laser beam focus of, e.g., 50 to $100 \mu \mathrm{m}$ diameter will always cover many different topographical areas at the same time, leading to detection of ions from salt contaminations and from peptide ions within the same spectrum.

\section{SMALDI Mass Analysis of Picospotted Samples}

Spotting or "microdispensing" of nano- or picoliter volumes of sample, for example of HPLC or capillary electrophoresis eluents, onto MALDI targets is a topic of high interest [41]. It has been observed earlier that such preparations behave rather differently in MALDI mass spectrometers compared to regular dried-droplet preparations or thin-film preparations. SMALDI mass analysis was found to be an ideal tool for investigating the microscopical desorption and ionization behavior of picospotted samples. Figure 12 shows, as an example, the ion images of a $\beta$-cyclodextrin picospot preparation obtained by SMALDI mass analysis with $1 \mu \mathrm{m}$ resolution at $262 \mathrm{~nm}$ laser wavelength. The investigated representative spot was prepared from a solution of $2.5^{*} 10^{-4} \mathrm{M} \beta$-cyclodextrin in $2^{*} 10^{-2} \mathrm{M} 2,5$-dihydroxybenzoic acid in ethanol/water. Microdroplets were formed and deposited employing a modified inkjet printer (HP deskjet 500C). These types of printers use the so called bubble jet technique, were droplets are ejected from microcavities by ultrafast heating. The advantage of the bubble jet technique over the more common piezo technique for microspotting is the considerably lower dead volume of the system. Negative effects of ultrafast heating on the integrity of biomolecules were not observed in our setup. Systematic investigations of this possible effect, however, are still lacking. The prepared volume per droplet was $2 \mathrm{pL}$, estimated from the number of droplets formed from a certain reservoir volume. The total amount of analyte ( $\beta$-cyclodextrin) per droplet therefore was in the range of 500 amol. The variation in this dimension was approximated to be less than $30 \%$ after microscopic examination of the size homogeneity of the spotted droplets.

Figure 12 shows the microscopically resolved ion abundances of different ion types. The signal of aluminum $(\mathrm{M}=70 \mathrm{u})$ in the lower right image resembles the topology of the target surface and vanishes in the area of the sample overlay. Matrix ions were formed from the complete picospot and were imaged using the signal of the dehydrated DHB ion $(m / z=137 \mathrm{u})$. Unlike the behavior of peptides (see Figure 10), the carbohy- 


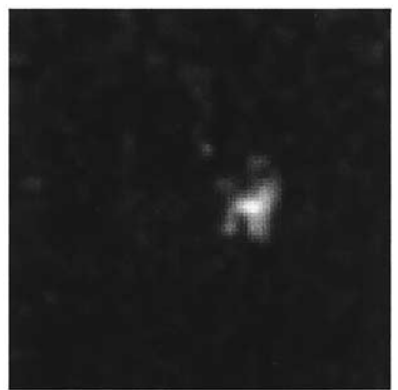

Analyte: ß-Cyclodextrin $[\mathrm{M}+\mathrm{Na}]^{+}=1158 \mathrm{u}$
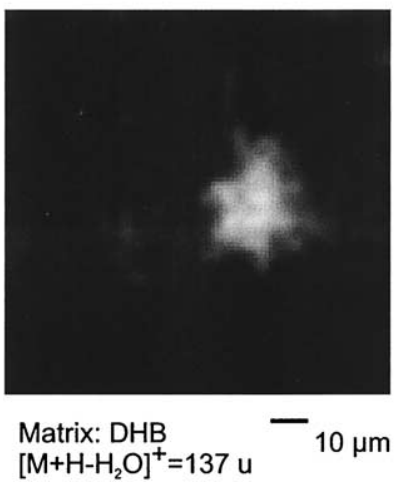

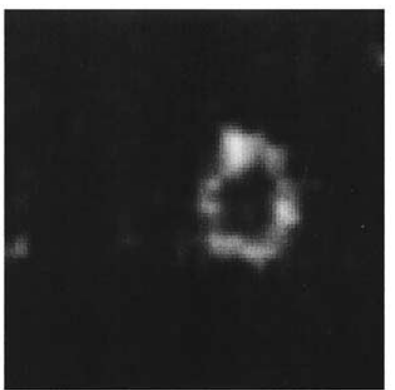

Impurities: Sodium $M^{+}=23 u$

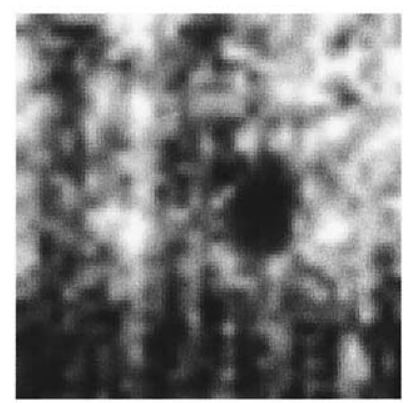

Target: Aluminum $\mathrm{M}^{+}=70 \mathrm{u}\left(\mathrm{Al}_{2} \mathrm{O}\right)$

Figure 12. Scanning microprobe matrix-assisted laser desorption/ionization (SMALDI) mass spectrometric image of a MALDI picospot preparation of $\beta$-cyclodextrin in 2,5-dihydroxybenzoic acid (DHB) matrix on a flat aluminum target. Approximately $2 \mathrm{pL}$ of sample solution were spotted per dot, containing $500 \mathrm{amol}$ of $\beta$-cyclodextrin. The image was scanned with $1 \mu \mathrm{m}$ step size at $262 \mathrm{~nm}$ laser wavelength and one laser shot per pixel. Each pixel of the dot covered a total amount of prepared analyte in the range of $800 \mathrm{zmol}$. See text for further explanation.

drate ions were obtained exclusively from the central part of the sample and not from the outer rim, expected to be formed of larger matrix crystals. Since the cationized analyte was monitored here, it is expected from the current understanding of the MALDI ion formation processes that carbohydrate molecules do not have to be incorporated into matrix crystals to become ionized by alkali attachment [42] and therefore should be observable from the microcritalline, flat area inside the rim. The images of MALDI picospots appear to confirm this idea.

Sodium ions $(m / z=23 \mathrm{u})$ were observed from the outer rim only, not from the central part of the spot, most probably because they were used up for cationization in the central part and were observed only as part of the detected quasi-molecular ions.

The sensitivity of the method is obviously very high. With a total sample amount of 500 amol per picospotted droplet, the prepared sample amount per pixel is only in the zeptomol range, estimating that analyte ions were detected from about 600 pixels. It is assumed that the detection limit is still considerably lower, suggesting a SMALDI detection limit which is at least in the subattomol range per $1 \mu \mathrm{m}$ pixel (as demonstrated) and is maybe even in the lower zeptomol range per $1 \mu \mathrm{m}$ pixel.

The above examples show that MALDI imaging
(SMALDI) is possible on the micrometer scale. Transfer of this instrumental capability to native samples (biological cells) requires the development of preparational procedures which are compatible with the prerequisites of matrix-assisted laser desorption ionization and which avoid migration of the imaged substituents during preparation. Application of SMALDI to biological and medical problems, as well as new matrix preparation techniques for SMALDI will be described in subsequent papers. Detectability of high-mass analyte molecules, such as larger proteins, is the topic of another investigation. It is not obvious that even if the MALDI process in general is compatible with $1 \mu \mathrm{m}$ laser spot sizes, large proteins can be desorbed and ionized intact from such small laser spots. Systematic investigations with variable focus conditions will document possible limitations and perspectives.

\section{Conclusion}

A couple of examples have shown the general capabilities of scanning laser microprobe mass spectrometry and of scanning microprobe matrix-assisted laser desorption ionization (SMALDI) mass spectrometry with a new instrument. They demonstrate the increase of informational content of two-dimensional concentra- 
tion images versus zero-dimensional mass spectrometry of selected spots. The extremely low focal depth leads to interesting possibilities for three-dimensional mass spectrometry but requires the development of dedicated software. Application of the SMALDI technique to biological problems is the focus of current investigations and will be reported soon.

\section{Acknowledgments}

Financial support by the Deutsche Forschungsgemeinschaft (Sp 314/3-1) and instrumental support by the Medical Institutions of the University of Duesseldorf are gratefully acknowledged. The authors would like to express their gratitude to Raimund Kaufmann (died 1997) who strongly supported the instrumental development project in its early phase. We would like to thank Peter Ingram (Duke University, NC) for helpful discussions and W. H. Schroeder (FZ Juelich) for providing the pine tree root sample. The Institute of Plasma Physics of the University of Duesseldorf is gratefully acknowledged for drilling the quartz lenses. Werner Bouschen and Volker Bökelmann helped to document the laser focus characteristics.

\section{References}

1. Hillenkamp, F.; Unsöld, E.; Kaufmann, R.; Nitsche, R. A High-Sensitivity Laser Microprobe Mass Analyzer. Appl. Phys. 1975, 8, 341-348.

2. Hillenkamp, F.; Unsöld, E.; Kaufmann, R.; Nitsche, R. Laser Microprobe Mass Analysis of Organic Materials. Nature 1975, 256, 119-120.

3. Van Vaeck, L.; Gijbels, R. Laser Microprobe Mass Spectrometry: Potential and Limitations for Inorganic and Organic Micro-Analysis. Part I. Technique and Inorganic Applications. Fresenius J. Anal. Chem. 1990, 337, 743-754.

4. Van Vaeck, L.; Gijbels, R. Laser Microprobe Mass Spectrometry: Potential and Limitation for Inorganic and Organic Micro-Analysis. Part II. Organic Applications. Fresenius J. Anal. Chem. 1990, 337, 755-765.

5. Odom, R. W.; Schueler, B. Laser Microprobe Mass Spectrometry: Ion and Neutral Analysis. In Laser and Mass Spectrometry; Lubman, D. M., Ed.; Oxford University Press: New York, Oxford, 1990; pp 103-137.

6. Spengler, B.; Karas, M.; Bahr, U.; Hillenkamp, F. Laser Mass Analysis in Biology. Ber. Bunsenges. Phys. Chem. 1989, 93, 396-402.

7. Seydel, U.; Heinen, H. J. First Results on Fingerprinting of Single Mycobacteria Cells with LAMMA. Recent Dev. Mass Spectrom. Biochem. Med. 1980, 6, 489.

8. Böhm, R. Sample Preparation Technique for the Analysis of Vegetative Bacteria Cells of the Genus Bacillus with the Laser Microprobe Mass Analyzer (LAMMA). Fres. Z. Anal. Chem. 1981, 308, 258-259.

9. Böhm, R.; Kapr, T.; Schmitt, H. U.; Albrecht, J.; Wieser, P. Application of the Laser Microprobe Mass Analyzer (LAMMA) to the Differentiation of Single Bacterial Cells. J. Anal. Appl. Pyrolysis 1985, 8, 449-461.

10. Karas, M.; Bachmann, D.; Bahr, U.; Hillenkamp, F. MatrixAssisted Ultraviolet Laser Desorption of Non-Volatile Compounds. Int. J. Mass Spectrom. Ion Processes 1987, 78, 53-68.

11. Karas, M.; Bachmann, D.; Hillenkamp, F. Influence of the Wavelength in High-Irradiance Ultraviolet Laser Desorption Mass Spectrometry of Organic Molecules. Anal. Chem. 1985, 57, 2935-2939.
12. Spengler, B.; Bahr, U.; Karas, M.; Hillenkamp, F. Excimer Laser Desorption Mass Spectrometry of Biomolecules at 248 and 193 nm. J. Phys. Chem. 1987, 91, 6502-6506.

13. Karas, M.; Hillenkamp, F. Laser Desorption Ionization of Proteins with Molecular Masses Exceeding 10,000 Daltons. Anal. Chem. 1988, 60, 2299-2301.

14. Karas, M.; Bahr, U.; Gießmann, U. Matrix-Assisted Laser Desorption Ionization Mass Spectrometry. Mass Spectrom. Rev. 1991, 10, 335-357.

15. James, P. Proteom Research: Mass Spectrometry. Springer Verlag: Berlin, 2001, pp 1-8.

16. Cole, R. B. Electrospray Ionization Mass Spectrometry. John Wiley \& Sons: New York, 1997, pp 383-570.

17. Spengler, B. Postsource Decay Analysis in Matrix-Assisted Laser Desorption Ionization Mass Spectrometry of Biomolecules. J. Mass Spectrom. 1997, 32, 1019-1036.

18. Li, L.; Garden, R. W.; Sweedler, J. V. Single-Cell MALDI: A New Tool for Direct Peptide Profiling. Trends Biotechnol. 2000, 18, 151-160.

19. van Veelen, P. A.; Jimenez, C. R.; Li, K.W.; Wildering, W. C.; Geraerts, W. P. M.; Tjaden, U. R.; van der Greef, J. Direct Peptide Profiling of Single Neurons by Matrix-Assisted Laser Desorption-Ionization Mass Spectrometry. Org. Mass Spectrom. 1993, 28, 1542-1546.

20. Jespersen, S.; Chaurand, P.; van Strien, F. J. C.; Spengler, B.; van der Greef, J. Direct Sequencing of Neuropeptides in Biological Tissue by MALDI-PSD Mass Spectrometry. Anal. Chem. 1999, 71, 660-666.

21. Jimenez, C. R.; Burlingame, A. L. Ultramicroanalysis of Peptide Profiles in Biological Samples Using MALDI Mass Spectrometry. Exp. Nephrol. 1998, 6, 421-428.

22. Jimenez, C. R.; Li, K. W.; Dreisewerd, K; Spijker, S.; Kingston, R.; Bateman, R. H.; Burlingame, A. L.; Smit, A. B.; van Minnen, J.; Geraerts, W. P. M. Direct Mass Spectrometric Peptide Profiling and Sequencing of Single Neurons Reveals Differential Peptide Patterns in a Small Neuronal Network. Biochemistry 1998, 37, 2070-2076.

23. Chaurand, P.; Stoeckli, M.; Caprioli, R. M. Direct Profiling of Proteins in Biological Tissue Sections by MALDI Mass Spectrometry. Anal. Chem. 1999, 71, 5263-5270.

24. Li, L.; Garden, R. W.; Romanova, E. V.; Sweedler, J. V. In Situ Sequencing of Peptides from Biological Tissues and Single Cells Using MALDI-PSD/CID Analysis. Anal. Chem. 1999, 71, 5451-5458.

25. Gusev, A. I.; Vasseur, O. J.; Proctor, A.; Sharkey, A. G.; Hercules, D. M. Imaging of thin-layer chromatograms using matrix-assisted laser desorption/ionization mass spectrometry. Anal. Chem. 1995, 67, 4565-4570.

26. Caprioli, R. M.; Farmer, T. B.; Gile, J. Molecular Imaging of Biological Samples: Localization of Peptides and Proteins Using MALDI-TOF MS. Anal. Chem. 1997, 69, 4751-4760.

27. Stoeckli, M.; Farmer, T. B.; Caprioli, R. M. Automated Mass Spectrometry Imaging with a Matrix-Assisted Laser Desorption Ionization Time-of-Flight Instrument. J. Am. Soc. Mass Spectrom. 1999, 10, 67-71.

28. Zhang, H.; Stoeckli, M.; Andren, P. E.; Caprioli, R. M. Combining Solid-Phase Preconcentration, Capillary Electrophoresis and Off-Line Matrix-Assisted Laser Desorption/Ionization Mass Spectrometry: Intracerebral Metabolic Processing of Peptide E in Vivo. J. Mass Spectrom. 1999, 34, 377-383.

29. Garden, R. W.; Sweedler, J. V. Heterogeneity within MALDI Samples as Revealed by Mass Spectrometric Imaging. Anal. Chem. 2000, 72, 30-36.

30. Stoeckli, M.; Chaurand, P.; Hallahan, D. E.; Caprioli, R. M. Imaging Mass Spectrometry: A New Technology for the Analysis of Protein Expression in Mammalian Tissues. Nat. Med. 2001, 7, 493-496. 
31. Todd, P. J.; Schaaff, T. G.; Chaurand, P.; Caprioli, R. M. Organic Ion Imaging of Biological Tissue with Secondary Ion Mass Spectrometry and Matrix-Assisted Laser Desorption/ Ionization. J. Mass Spectrom. 2001, 36, 355-369.

32. Niehuis, E.; van Velzen, P. N. T.; Lub, J.; Heller, T.; Benninghoven, A. High Mass Resolution Time-of-Flight Secondary Ion Mass Spectrometry-Application to Peak Assignments. Surf. Interface Anal. 1989, 14, 135.

33. Stockle, R.; Setz, P.; Deckert, V.; Lippert, T.; Wokaun, A.; Zenobi, R. Nanoscale Atmospheric Pressure Laser AblationMass Spectrometry. Anal. Chem. 2001, 73, 1399-1402.

34. Bergmann, L. Lehrbuch der Experimentalphysik/Bergmann; Schaefer Band 3. Optik, 8. de Gruyter: Berlin, New York, 1987; p 401.

35. Hillenkamp, F.; Bahr, U.; Karas, M.; Spengler, B. Mechanisms of Laser Ion Formation for Mass Spectrometric Analysis. Scan. Microscopy Suppl. 1 1987, 33-39.

36. Strupat, K.; Kampmeier, J.; Horneffer, V. Investigations of 2,5-DHB and Succinic Acid as Matrices for UV and IR MALDI. Part II: Crystallographic and Mass Spectrometric Analysis. Int. J. Mass Spectrom. 1997, 169, 43-50.

37. Horneffer, V.; Dreisewerd, K.; Ludemann, H. C.; Hillenkamp, F.; Lage, M.; Strupat, K. Is the Incorporation of Analytes into
Matrix Crystals a Prerequisite for Matrix-Assisted Laser Desorption/Iionization Mass Spectrometry? A study of Five Positional Isomers of Dihydroxybenzoic Acid. Int. J. Mass Spectrom. 1999, 187, 859-870.

38. Bökelmann, V.; Spengler, B.; Kaufmann, R. Dynamical Parameters of Ion Ejection and Ion Formation in Matrix-Assisted Laser Desorption/Ionization. Europ. Mass Spectrom. 1995, 1, 81-93.

39. Dai, Y.; Whittal, R. M.; Li, L. Confocal Fluorescence Microscopic Imaging for Investigating the Analyte Distribution in MALDI Matrices. Anal. Chem. 1996, 68, 2494-2500.

40. Hanton, S. D.; Clark, P. A. C.; Owens, K. G. Investigations of Matrix-Assisted Laser Desorption/Ionization Sample Preparation by Time-of-Flight Secondary Ion Mass Spectrometry. J. Am. Soc. Mass Spectrom. 1999, 10, 104-111.

41. Miliotis, T.; Marko-Varga, G.; Nilsson, J.; Laurell, T. Development of Silicon Microstructures and Thin-Film MALDI Target Plates for Automated Proteomics Sample Identifications. J. Neurosci. Methods 2001, 109, 41-46.

42. Karas, M.; Glückmann, M.; Schäfer, J. Ionization in MatrixAssisted Laser Desorption/Ionization: Singly Charged Molecular Ions are the Lucky Survivors. J. Mass Spectrom. 2000, 35, $1-12$. 